\section{Questión}

Periodismo / Comunicación ISSN 1669-6581
- Av. $44 \mathrm{~N}^{\circ} 676,1^{\circ}$ piso

CP 1900 - La Plata - Argentina

www.perio.unlp.edu.ar/question

Covid-19, desigualdad y reflexiones desde la periferia.

Marta Pilar Bianchi y Luis Sandoval

https://doi.org/10.24215/16696581e347

\title{
Covid-19, desigualdad y reflexiones desde la periferia.
}

\section{Covid-19, inequality and reflections from the periphery.}

\author{
Marta Pilar Bianchi \\ martapilarbianchi@gmail.com \\ Luis Ricardo Sandoval \\ luisricardo.sandoval@gmail.com
}

Universidad Nacional de la Patagonia San Juan Bosco Grupo de Trabajo sobre Internet, Tecnología y Cultura

\section{Palabras Clave \\ Desigualdad - Periferia - Alternativas - Buena vida}

\section{Keywords}

Inequality - Periphery - Alternatives - Good Life

En diciembre de 2019 los medios internacionales se hicieron eco de las primeras noticias vinculadas a la aparición de un nuevo virus en Wuhan, China, luego confirmado como SARSCoV-2 y bautizado prontamente como Covid-19, o coronavirus del año 2019.

Para fines de mayo de 2020, casi un semestre después, los contagiados en el mundo ascienden a 5,8 millones y se contabilizan 362 mil muertes. Son números para poner en perspectiva, considerando los 9 millones de personas que según la OMS mueren anualmente en el mundo a causa de cáncer, solo por poner un ejemplo. Pero no es éste el eje de la reflexión que aquí queremos compartir, tan solo es un indicador, un marco para contextualizar el asunto.

Las alertas ante la propagación del virus activaron distintas medidas en cada región para mitigar los efectos de su avance. En Argentina, el gobierno nacional decidió iniciar el 20 de marzo el 
Aislamiento Social, Preventivo y Obligatorio (ASPO), como forma de lentificar el avance de la pandemia y proteger del colapso al sistema de salud ante la posibilidad de una escalada de casos.

Ahora bien, esta situación reveló con crudeza algunos rasgos de la configuración de nuestras sociedades, especialmente aquellos ligados a la asimetría en la distribución de la riqueza. Tal vez hoy debiéramos pensar en soluciones de fondo y a largo plazo, no solo ante la posibilidad de que las pandemias mundiales puedan repetirse, sino simplemente por una cuestión sencillamente ética, humana y política.

Pensemos en primer lugar en las ciudades de Argentina (y de América Latina, pues son patrones similares): grandes urbes con elevada concentración de personas cuya infraestructura de servicios, salud, educación, gobierno, medios masivos, transporte, se centralizan por capas: en la capital nacional, en las capitales provinciales, en las grandes ciudades después de ellas. Las provincias patagónicas, por ejemplo, con baja densidad poblacional, son dependientes de la capital nacional y de algunas grandes ciudades argentinas para la asistencia especializada de salud de sus habitantes o la concreción de estudios universitarios de grado y posgrado según el área de conocimiento de la cual se trate. La posibilidad de contagio y el imperativo de disminuir al máximo los contactos (espíritu del ASPO) vienen revelando una necesidad urgente de replantear la infraestructra de las ciudades, procurando descentralizar los servicios y así descomprimir los grandes aglomerados. En otro registro, también se evidencia, incluso, la necesidad de crear nodos que descentralicen las grandes ciudades, evitando que los ciudadanos se vean obligados a desplazamientos de más de 60 minutos para llegar diariamente a sus trabajos, a los sistemas de salud o a los establecimientos educativos. No se trata solo de pandemia: se trata de pensar en una mejor calidad de vida, en una cotidianeidad menos sufriente. En otro registro, la pobreza, cuyo correlato es la creciente concentración de riqueza, características del capitalismo, nos obliga a pensar en las condiciones tremendamente desiguales en las que se encuentran cuatro de cada diezi de nuestros conciudadanos para afrontar esta pandemia: viviendas precarias, hacinamiento, falta de agua corriente, trabajos precarios, trayectorias escolares truncas, solo por mencionar los datos más evidentes. Cuando Ramona Medina denunció la falta de agua en Villa 31 se convirtió en la portavoz de los barrios pobres de las grandes ciudades, pero también en la de muchos barrios y pequeñas localidades de nuestro territorio argentino más extenso. Lo que puso en evidencia esta pandemia es una 
situación estructural que permite también que el dengue se propague sin control en el litoral argentino (32 mil casos para esta fecha), o que la diarrea o los distintos tipos de influenza sean enfermedades cuya prevalencia es mayor en las regiones del Noroeste y Noreste argentinas, 0 que la hidatidosis tenga una incidencia de 5,7 casos cada 100.000 habitantes en Patagoniaii. Todas enfermedades asociadas a la pobreza. ¿Seguiremos indiferentes como comunicadores y como ciudadanos, como agentes políticos, ante esta realidad?

Boaventura de Souza Santos señala este momento de la pandemia como un excelente catalizador para mostrar con profunda evidencia que el capitalismo produce pobreza y redobla el sufrimiento en los más vulnerables. A eso nos referimos.

Conectado con lo anterior, una línea especial merece el ámbito de la salud: esta situación ha revelado la debilidad de los sistemas sanitarios en toda la extensión del territorio argentino. Por ejemplo, en la ciudad de Comodoro Rivadavia, al sur de la provincia de Chubut, con 300.000 habitantes, había al momento de inicio del ASPO, 15 camas de terapia intensiva y cinco respiradores. ¿Cómo no instalar el aislamiento con una estructura tan endeble a lo largo del territorio para hacer frente a una pandemia de estas características? Ojalá sea ésta una oportunidad para que políticamente se decida priorizar una mejor y más equitativa asistencia en salud pública en todas las regiones de nuestro país.

Ahora bien, como comunicadores, también miramos nuestros territorios con preocupación cuando el tratamiento mediático de la pandemia ocluye toda referencia a temáticas locales urgentes. Es el caso de la provincia de Chubut, donde los empleados estatales llevan desde agosto de 2019 percibiendo sus salarios de manera escalonada y con un atraso para algunos rangos de hasta dos meses (a mayo de 2020). Las agendas locales y nacionales han incluido de manera muy residual este tema desde el inicio de la ASPO. En la provincia, la disposición nacional de aislamiento preventivo fue oportunamente aprovechada para silenciar los reclamos en las calles que llevaban adelante docentes, personal sanitario y empleados judiciales. Bajo una modalidad de extrema dureza, que excede las restricciones impuestas por el Ejecutivo Nacional, el ministro de seguridad de la provincia implementó un operativo que ha recibido críticas y denuncias desde distintos sectoresiii. Estos planteamientos han ocupado poco espacio en los medios locales y casi ninguno en los medios nacionales. Aún cuando la situación en la provincia -pocos casos declarados, ausencia de circulación comunitaria del virus- dista de la gravedad que reviste en otros lugares, el miedo instalado ante la potencial amenaza ha justificado el 
silenciamiento de estos trabajadores y confinado sus reclamos a las redes sociales. Esto nos lleva a preguntarnos si los sistemas de representación gremial en estos tiempos no deberían ser repensados... ¿Qué pasará si la pandemia se extiende en el tiempo? ¿O si hay pandemias recurrentes? La precarización del empleo y la flexibilización laboral parecen encontrar un contexto que las justifica, aún cuando se enmascare con el rostro a la moda del teletrabajo. Será necesario reinventar las formas de representación de los trabajadores e incluir en las nuevas agendas las problemáticas que emergen de la mano de la incorporación de la tecnología digital interactiva.

Es que la tecnología -que a nadie sorprende que ocupe un lugar absolutamente central en nuestras sociedades- ha evidenciado y potenciado su ubicuidad en el contexto de la pandemia, posibilitando -como un Jano bifronte- tanto aplicaciones que potencian sus bondades como otras que profundizan formas de opresión y control. En Patagonia, a pesar de que las estadísticas (realizadas en los centros urbanos) reflejan un alto índice de acceso a Internet, la realidad en el territorio es dispar: desde lugares con un acceso casi mínimo o inexistente, como comunas rurales de la meseta central, hasta localidades con un acceso de mejor pero desigual calidad. Nuevamente se ubica en la agenda la cuestión de la equidad: si a las dificultades estructurales mencionadas al principio de estas reflexiones le sumamos la desconexión, entonces en estos tiempos especiales ¿Cómo un ciudadano puede acceder a las propuestas virtuales de los establecimientos educativos? ¿Cómo puede trabajar? ¿Cómo tramita un permiso de circulación? ¿Cómo saca un turno? Evidentemente la problemática de la brecha digital dista de haberse agotado, tanto en lo que hace a la conectividad como a lo que la UNESCO denominó oportunamente (y hace 15 años) la brecha cognitiva. Es que, sobrepuesto a la cuestión del acceso, una proporción importante de ciudadanos no poseen la suficiente alfabetización digital para operar de manera autónoma con todas estas opciones que las estructuras burocráticoadministrativas imponen en el contexto de la pandemia. Es más: esa agenda que debe encarar un pensamiento crítico preocupado por las problemáticas comunicacionales de este siglo debe ir más allá e incluir la indiscutible capacidad de las tecnologías para ser utilizadas como mecanismos de regulación y control. También la pandemia evidencia este aspecto, desde las sutiles apps para autodiagnóstico que monitorean posibles casos de Covid hasta la posibilidad no implementada en Argentina, pero si en otros países- de monitorear a través de drones la actividad y estado de salud de los ciudadanos ¿Puede leerse esto como un avance sobre los 
derechos individuales? Se trata sin duda de una expresión de las potencialidades anatomo y biopolíticas que encierra la aplicación de las tecnologías. También aquí se plantea la ambivalencia: la contracara de esta cuestión la constituye la tecnología como posibilitadora del mantenimiento -aunque sea provisorio- de la cotidianeidad a pesar del aislamiento, el mantenimiento de los lazos sociales, del trabajo, la posibilidad de expresión por medios alternativos, el acceso a la información, la expresión del arte y del ocio.

Aún en la coyuntura, resulta evidente que esta especial circunstancia nos invita a reflexionar sobre la fragilidad de nuestra condición humana, sobre los peligros para nosotros mismos en tanto especie si desconocemos al otro, nuestro conciudadano, nuestro vecino, en su sufrimiento, en su fragilidad. De un modo inesperado, este virus nos obliga a reconocer el valor único de la vida, y a concluir que esta forma que los humanos hemos creado de organización político económica no nos posibilita una "buena vida". Tal vez, porque siempre vale la pena apostar a la esperanza, esta sea una gran oportunidad para pensar seriamente en alternativas que nos dignifiquen.

\section{Referencias}

Análisis de la Situación de Salud en la República Argentina. Ministerio de Salud de la Nación Argentina. 2018

Boaventura de Souza Santos (2020) A Cruel Pedagogia do Vírus. Ediciones Almedina. Coimbra, Portugal.

Encuesta Nacional sobre acceso y uso de Tecnologías de la Información y la Comunicación (ENTIC) (2015) Instituto Nacional de Estadísticas y Censos de la República Argentina. https://www.indec.gob.ar/uploads/informesdeprensa/entic

Grupo Interdisciplinario de Estudios de Crisis Sociales. En https://www.facebook.com/giecs.humanidades

Informe Técnico Encuesta Permanente de Hogares. Incidencia de la pobreza y de la indigencia. Resultados del segundo semestre de 2019. Instituto Nacional de Estadísticas y Censos de la República Argentina. 


\section{Notas}

i El índice de pobreza para el segundo semestre de 2019 en Argentina es de 35,5\%, según datos del INDEC. ii $\quad$ Datos del Ministerio de Salud de Presidencia de la Nación Argentina para 2019.

iii El grupo Interdisciplinario de Estudios de Crisis Sociales, constituido por profesores e investigadores de la Facultad de Humanidades y Ciencias Sociales de la UNPSJB, reúne notas que relatan cronologías y hechos diversos alrededor de esta situación. 